\title{
(Des)naturalización y elección: emergencias en la parentalidad y el parentesco de lesbianas, gays, bisexuales y transexuales
}

\author{
(De)Naturalization and Election: Emergencies in Lesbian, \\ Gay, Bisexual and Transsexual Kinship and Parenting
}

\author{
José Ignacio Pichardo Galán \\ Universidad Complutense de Madrid, España \\ Matías de Stéfano Barbero \\ CONICET-Universidad de Buenos Aires, Argentina \\ M. Laura Martín-Chiappe \\ Instituto de Lengua, Literatura y Antropología, CSIC \\ Universidad Autónoma de Madrid, España
}

\section{RESUMEN}

En los procesos de transformación de las estructuras familiares que han vivido las sociedades europeas, y específicamente la española, en las últimas décadas, las familias formadas por lesbianas, gays, bisexuales y transexuales (LGBT) han ocupado un lugar protagonista. La hipótesis de partida de nuestro trabajo de investigación exploratorio ha sido que, conjuntamente con las rupturas que las llamadas familias arcoíris (las formadas por personas LGBT) han incorporado a las concepciones de la familia, las nuevas situaciones familiares en este colectivo se interpretan reproduciendo algunos de los elementos del modelo hegemónico vigente. Así, aunque existen emergencias en lo que se refiere al acceso a la parentalidad y a la división sexual de las tareas reproductivas y domésticas, se mantiene generalmente la hegemonía del modelo de familia nucleada en torno a la pareja o el deseo de lazos genéticos que legitimen la filiación. Asimismo, es de suma importancia reconocer el proceso de transformación creativa del parentesco tradicional que este colectivo lleva adelante, cuyo correlato es la revisión y redefinición del parentesco en su conjunto.

Palabras clave: Familia; Parentesco; Gays y Lesbianas; Homoparentalidad; LGBT.

\section{SUMMARY}

In recent decades, lesbian, gay, bisexual and transgender (LGBT or rainbow) families have become key players in the transformation processes affecting family structures in European societies, and specifically in Spain. Our research hypothesis is that, even as rainbow families have caused ruptures in pre-existing concepts of family, they have also reproduced certain contemporary hegemonic models. There have been changes in relation to access to parenting and the sexual division of reproductive and domestic work. However, the hegemonic model of the nuclear family 
is still based on "coupling" and the desire to maintain genetic ties in order to legitimise filiation. As such, LGBT families are engaged in a creative transformation of traditional kinship, broadening and redefining the concept to incorporate same-sex and heterosexual families.

Key words: Family; Kingship; Gays and Lesbians; LGBT Parenting.

\section{INTRODUCCIÓN}

Al tener en cuenta que el parentesco no es producto de una realidad natural preexistente, sino que se funda en relaciones sociales presentadas como naturales (Meillasoux 2001), los cambios culturales y las experiencias emergentes de diversos actores sociales nos llevan a otorgar significados novedosos a la realidad de la familia y de las relaciones que se incluyen bajo el paraguas del parentesco. Tanto el concepto de familia como las relaciones de parentesco están expuestos a continuas transformaciones y redefiniciones de las que ya han dado cuenta numerosos científicos sociales (Segalen 1992). Desde el final del último siglo, podemos reconocer una serie de procesos socioculturales que han transformado las relaciones interpersonales vinculadas con el cuidado, la sexualidad y la reproducción social y biológica en las sociedades occidentales (Piella y Fons 2010). Cadoret (2003) recoge algunos de los múltiples factores que han posibilitado en las últimas décadas el cuestionamiento del modelo tradicional de parentesco en el mundo occidental: el desarrollo del individualismo que se expresa en un mayor poder de decisión sobre la vida propia y mayor reflexión sobre el deber y el querer; el progresivo culto a la expresión del yo; la autonomía de la sexualidad femenina frente a la reproducción; las modificaciones en las relaciones de dependencia/independencia económica de las mujeres; el cuestionamiento del modelo hombre proveedor/mujer cuidadora y la división sexual del trabajo; la introducción de la educación y el trabajo como prioridades en las trayectorias de vida de las mujeres o el progreso de las técnicas de reproducción asistida (TRA), por citar sólo algunos de los factores más relevantes.

En estos procesos de transformación de las estructuras familiares que han vivido en las últimas décadas las sociedades europeas, y específicamente la española, las familias formadas por lesbianas, gays, bisexuales y transexuales (LGBT) han ocupado un lugar protagonista. Así, el colectivo LGBT está contribuyendo activamente a la transformación de ese modelo a través de la visibilización y la demanda de legitimación de ciertas realidades que, si bien existían previamente, permanecían ocultas. Si ya se habían dado los cambios sociales que permitieron desvincular la sexualidad de la reproducción y la reproducción de la sexualidad, la mayoría de las personas no heterosexuales han profundizado esta ruptura al acceder a la parentalidad (maternidad y paternidad) por vías alternativas a la relación coital heterosexual. Se incide así en la idea de que ni la sexualidad ni la reproducción van a ser ni exclusivamente coitales ni heterosexuales.

En este contexto, el marco normativo que regula la filiación también se ve obligado a ajustarse a las nuevas realidades, que van más allá de la descendencia de parejas heterosexuales, para regular también relaciones de filiación de mujeres u hombres solteros y sus descendientes, así como los casos de parejas del mismo sexo. Gracias 
a las leyes de reproducción asistida, matrimonio y adopción aprobadas en España a finales del siglo XX y principios del $\mathrm{XXI}^{1}$, "los individuos y las parejas del mismo sexo son ahora reconocidos como agentes de reproducción tanto biológica como social" (Pichardo 2011: 25). Siguiendo esta línea de reflexión, puede entenderse que la ruptura del continuo coito/alianza/filiación adquiere un estatus de reconocimiento oficial una vez que la filiación de los niños y niñas con padres o madres del mismo sexo es reconocida legalmente.

Asimismo, el matrimonio ya no tiene por qué ser la base exclusiva en la formación de la familia, ni viceversa. Partiendo de la realidad que reconoce el matrimonio como contrato entre dos personas, se hace necesario pensar en las formas en las que jurídicamente se reconoce y formaliza la institución familiar, y algunas de las modificaciones que ha sufrido, especialmente tras la legalización en España del matrimonio entre personas del mismo sexo en el año 2005.

La aprobación del matrimonio entre parejas del mismo sexo, por la naturaleza inherentemente pública que tiene la institución matrimonial, contribuyó a la visibilización no sólo de las individualidades LGBT, sino también de las parejas homosexuales y finalmente de las llamadas familias homoparentales en espacios sociales que tendían a invisibilizarlos (centros escolares y sus asociaciones de madres y padres, espacios de ocio familiar, documentación oficial y ámbito jurídico, entre otras). Este ordenamiento y distribución de los espacios "familiarizados" y "familiarizantes" - pensemos en la multitud de escenas, actividades y lugares reservados a las familias con hijos/as en nuestra sociedad- establece una suerte de barrera social; una distancia simbólica entre las familias heterosexuales y las individualidades LGBT que no compartieron, al menos de forma visible, estos espacios hasta que los segundos no alcanzaron el estatus de familia legitimada y, por consiguiente, adquirieron presencia manifiesta en estas actividades.

Así, lo que Fassin denomina "las familias sexuales", esto es, las familias LGBT, llevan al terreno público la centralidad y la potencialidad de la sexualidad, no sólo como una cuestión hedonística, sino como una herramienta para construir vínculos: «la sexualidad fue el paradigma que ayudó a pensar cuán nuevas y alternativas eras las familias creadas con la premisa de la elección y no de la sangre" (Fassin 2011: 8). Las familias LGBT, aun conformando un colectivo diverso y heterogéneo, nos muestran que la sexualidad y la familia no habitan mundos separados, cuestionando la normatividad y la univocidad de estos términos al ponerlos en relación de múltiples maneras. Estas familias van a resultar unas de las protagonistas del proceso de desinstitucionalización de la familia nuclear como modelo único, dejando paso a una realidad social compuesta por diversos modelos familiares. Contribuyen, pues, a poner en cuestión la supuesta indisolubilidad de relaciones entre sexualidad, procreación, residencia, alianza y filiación pero, como veremos en la siguiente hipótesis y a lo largo de este artículo, no están exentas de reproducir determinados elementos de los modelos previos de representación de la familia y el parentesco.

\footnotetext{
${ }^{1}$ Ley de adopción (21/1987), Ley sobre técnicas de reproducción asistida (35/1988), Ley de matrimonio igualitario (13/2005) y Ley sobre técnicas de reproducción humana asistida (14/2006).
} 


\section{HIPÓTESIS Y TRABAJO DE CAMPO}

Partimos de la hipótesis de que, conjuntamente con las rupturas que las familias LGBT han incorporado a las concepciones de la familia, las nuevas situaciones familiares en este colectivo reproducen algunos de los elementos del modelo hegemónico de familia que ha estado vigente en las últimas décadas.

La producción de datos para este trabajo de investigación prospectiva se realizó en el mes de mayo de 2012, durante el II Encuentro Europeo de Familias LGBT, realizado en Lloret de Mar (Girona). Según las cifras aportadas por la organización, participaron más de cuatrocientas familias —aproximadamente mil personas—, procedentes de más de catorce países, fundamentalmente europeos, aunque también se desplazaron personas desde Canadá y Estados Unidos ${ }^{2}$. El Encuentro contaba con un amplio programa de actividades como talleres, conferencias, excursiones, grupos de trabajo, actividades infantiles, disfrute de zonas comunes del hotel, tiempo libre y espacios para el ocio.

Para desarrollar la investigación exploratoria, se realizó un trabajo de campo intensivo por parte de ocho investigadores e investigadoras durante los 4 días de duración del Encuentro ${ }^{3}$. La metodología utilizada comprendió tanto técnicas cuantitativas como cualitativas. Con el fin de tener un conocimiento panorámico de la situación de las familias LGBT asistentes al Encuentro, se pasaron y recogieron 151 cuestionarios (algunos autoadministrados y otros completados por el equipo en entrevistas) en los que se vieron representadas personas de todos los países asistentes. Si bien los resultados de este pequeño sondeo no tienen validez estadística, sí nos permiten aventurar algunas reflexiones que deberían ser contrastadas de forma cuantitativa en un estudio posterior. Además, se realizaron 32 entrevistas informales y observación participante tanto en los espacios oficiales del Encuentro como en los momentos informales de intercambio en los que las familias participaron (comidas, pausas de café, excursiones). A continuación recogemos algunos de los aspectos abordados en este estudio para dar cuenta de los procesos de cambio y continuidad que pretendemos analizar en este artículó ${ }^{4}$.

${ }^{2}$ Las personas y familias que participan en este tipo de encuentros presentan características que no pueden extrapolarse al conjunto de familias homoparentales: visibilidad, activismo y participación en redes, entre otros elementos. Sin embargo, sus discursos y prácticas sí parecen pertinentes a la hora de analizar las emergencias que se producen en este colectivo.

3 El equipo de investigación, coordinado por José Ignacio Pichardo Galán, estuvo integrado por Matías de Stéfano Barbero, Ma Laura Martín Chiappe, Sonia Román Beitía, Alba García Muñoz, Laura Muelas de Ayala, Ane Sesma Gracia y José Martín Vela.

${ }^{4}$ Las reflexiones expuestas en este artículo no se construyen únicamente a partir de este trabajo prospectivo, sino que se enriquecen con otros estudios realizados por los autores de este artículo. Por una parte, el trabajo de campo de la tesis doctoral de José Ignacio Pichardo Galán (2009) sobre homosexualidad y nuevos modelos familiares. Por otra, la investigación en proceso sobre familias LGBT en España, que se lleva a cabo en el marco del proyecto paneuropeo de investigación "Families and Societies", en el que Pichardo y de Stéfano participan en la realización y análisis de 30 entrevistas semiestructuradas en profundidad a personas LGBT (2013-2015). 
MATERNIDAD Y PATERNIDAD: EL PROTAGONISMO DE LAS TÉCNICAS DE REPRODUCCIÓN ASISTIDA

El primero de nuestros objetivos era conocer las diferentes maneras en las que las familias asistentes al Encuentro habían accedido a la parentalidad. De acuerdo con la información extraída de las encuestas realizadas, podemos decir que en una amplia mayoría, las familias accedieron a la paternidad y la maternidad a través de la inseminación clínica (41\%), la adopción (33\%) y a partir de la autoinseminación en el hogar (12\%). Otra forma de acceso a la parentalidad, estudiado para el caso francés por Cadoret (2003), es la coparentalidad (sistema en el que hay más de dos personas que son padres y/o madres) pero durante el trabajo de campo en el Encuentro de familias solamente una persona dijo haber accedido a la parentalidad a partir de dicho sistema.

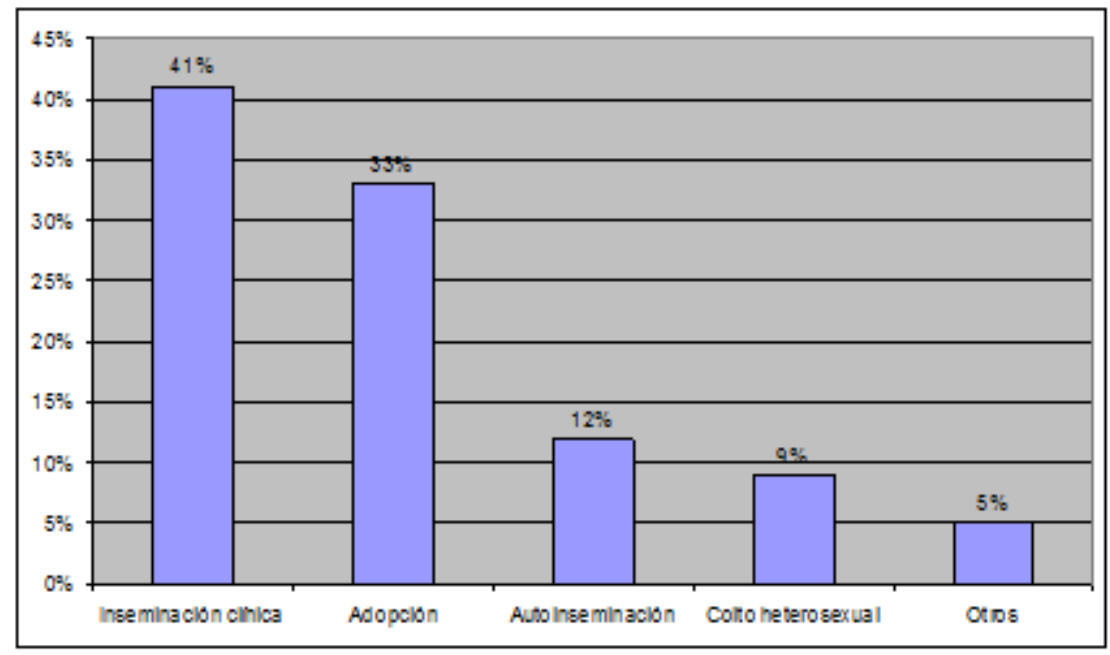

GRÁFICO 1 (autoría propia).

Aunque la adopción es la segunda forma de acceso a la parentalidad en este grupo, durante el Encuentro predominaron los discursos sobre la reproducción asistida y la subrogación. Las imágenes y representaciones sobre la adopción y el acogimiento aparecían centradas en su vertiente internacional, mostrando carteles con fotos de niños y niñas afrodescendientes o mestizas, mientras que en la reproducción asistida y la subrogación se utilizaba imágenes de niñas y niños caucásicos.

Diversos institutos de reproducción tuvieron una visible presencia en los espacios del Encuentro, de hecho, las empresas de técnicas de reproducción asistida (TRA) figuran como colaboradoras del II Encuentro Europeo de Familias LGBT y financian parte de la organización y actividades que tienen lugar en el mismo. Se desarrollaron tanto una sesión especial de grupos de trabajo sobre "Gestación subrogada: men having babies", como dos sesiones especiales de presentación de empresas de gestación subrogada. Al mismo tiempo, existía una presencia continuada de estands en el hall 
del hotel en los que podía encontrarse abundante información a partir de folletos y revistas, y donde podían realizarse consultas particulares.

La fuerte implicación de las empresas del sector de la reproducción asistida, que tiene como corolario un importante apoyo económico a este tipo de eventos, es una realidad emergente que comienza a reflejarse en los escasos trabajos que desde las ciencias sociales abordan este tipo de temáticas. Alfredo Francesch (2012) es uno de los autores que nos señala los contactos y asociaciones entre las clínicas que ofertan TRA y empresas turísticas especializadas en el transporte y alojamiento de personas.

\section{"LA SANGRE ES MÁS ESPESA QUE EL AGUA": APUNTES SOBRE LA (DES)NATURALI- ZACIÓN DE LAS RELACIONES FAMILIARES EN LAS FAMILIAS LGBT}

La compleja relación entre las definiciones de matrimonio y familia y lo que es considerado legítimo por las instituciones y por el conjunto de la sociedad se revela en palabras de una de las mujeres griegas que contrajo matrimonio con su pareja durante el Encuentro cuando, durante una conversación en un grupo de debate, comentaba que "para la sociedad griega en particular si no tienes hijos no eres familia, no eres familia por casarte».

La homoparentalidad y las familias del arcoíris cuestionan la conexión biológica de los lazos familiares al poner de relieve que ésta es sólo una de las múltiples formas posibles de crear familias (Donoso 2002; Weston 2003). Pero, al mismo tiempo, la biología no desaparece, sino que se mantiene como referente en las familias homosexuales. Así, el vínculo genético que se identifica con el modelo de familia nuclear heterosexual continúa operando dentro del colectivo LGBT (Pichardo 2009).

Aunque el acceso a la parentalidad ofrece formas rupturistas con respecto a la concepción tradicional a través del coito genital heterosexual, quedan espacios en los que la costumbre y los modelos hegemónicos se hacen presentes en los discursos y prácticas homoparentales. Durante el Encuentro, uno de los discursos predominantes de las madres y padres LGBT es el deseo manifiesto de pasar por un proceso biológico para alcanzar la parentalidad. Aquí debemos introducir lo que Verena Stolcke denomina genomanía: la obsesión por compartir la carga genética con los niños y niñas de los que se asume su crianza (en Pichardo 2009: 241). Este vínculo genético actúa como naturalizador de algunas homoparentalidades y, al tiempo que cumple una función legitimadora, reproduce las concepciones hegemónicas que suponen que los miembros de una familia están ligados entre sí por un vínculo de sangre o genético.

Tal es así, que determinados padres y madres LGBT ponen los medios e invierten en ocasiones grandes esfuerzos personales y económicos para conseguir tener este vínculo genético con sus hijos e hijas5. Por ejemplo, siendo A y B dos mujeres en pareja, la estrategia para mantener esta conexión biogenética constaría de la siguiente ecuación: óvulo fecundado de A con semen de C (hermano de B) inseminado en la matriz de A o B. La importancia del vínculo genético y las estrategias para conse-

\footnotetext{
${ }^{5} \mathrm{Al}$ igual que ocurre a menudo con los padres y madres heterosexuales que no pueden acceder a la parentalidad a través del coito genital heterosexual, bien por cuestiones de esterilidad o bien por ser familias monoparentales.
} 
guirlo se amplían generalmente más allá del primer hijo o hija de la pareja. Reproduciendo el valor de los lazos genéticos, no es extraño llegar a conseguir fratrías consanguíneas para que los hijos/as sea hermanos/as "de verdad", es decir, compartan una carga genética común.

En este sentido, el valor atribuido a la reproducción asistida y a la subrogación se vincula también con la posibilidad de hacer una supuesta elección genética, posibilidad que no ofrecen otras alternativas como la adopción. Uno de los asistentes al Encuentro lo explica así: "Si dentro de unos años hacéis un estudio sobre los hijos de familias LGBT, te darás cuenta que los cerebros, los más listos, los 'Einsteins', son hijos de lesbianas [...] porque, ¿cómo sois madres las mujeres? La mayoría por inseminación, por lo que pilláis lo mejor».

A pesar de esta reflexión, debemos destacar que entre los hombres encuestados el 39,28\% son o quieren ser padres a través de la adopción. Para profundizar más en esta cuestión, cabría preguntarse por aquellos factores que intervienen en la elección de un método u otro para acceder a la parentalidad, tales como los ingresos económicos, el país de residencia, la legislación, los valores y creencias y, sin duda alguna, el sexo del futuro padre(s) o madre(s). Así, una pareja de hombres entrevistados en el Encuentro comentaban que habían optado por la subrogación no tanto porque desearan tener un lazo genético con sus hijos/as, sino porque la vía de la adopción era muy larga y complicada para una pareja de dos hombres, mientras que la subrogación, aunque cara, era mucho más fácil y rápida.

El valor atribuido a la naturaleza de las relaciones de parentesco entre algunas familias LGBT se vincula también con la posibilidad de hacer elecciones que van más allá de la conexión biogenética. Existen otras estrategias para naturalizar la relación de la madre gestante que no aporta su óvulo con la criatura en cuestión. Claudia Fonseca (2008: 5) advierte que deberíamos considerar lo que nos hemos tomado la libertad de denominar "fenomanía": se valora la importancia de $-\mathrm{y}$ se recurre a estrategias informales para- hacer parecer al hijo/a de la pareja fenotípicamente con ésta, con el fin de naturalizar la relación tanto dentro de la propia familia como frente a la familia de origen y a la sociedad al completo. La autora nos presenta los ejemplos de las familias judías o afrocaribeñas, entre las que quizás la importancia de "ser" es relativa frente a la de "parecer" hijo o hija ya no de la pareja, sino del grupo étnico de origen en su conjunto.

Teniendo en mente estos conceptos y la propuesta de Weston (2003) sobre las llamadas "familias de elección", durante el Encuentro pedimos a las familias que seleccionaran aquellas personas que considerasen parte de su propia familia, con el objetivo de conocer de qué manera el colectivo LGBT está interpretando la composición de esta institución. Los resultados revelan que, frente a la tesis de Weston, que afirma que la comunidad LGBT redefine las concepciones tradicionales de familia a través de la elección de los miembros que las constituyen, puede observarse cómo las tres opciones más repetidas son hijos/hijas (88\%), madres/padres (87\%) y hermanos/hermanas (82\%). Se colige entonces que el vínculo genético como base del modelo de familia nuclear sigue vigente dentro del colectivo, especialmente para el caso de las culturas mediterráneas, donde las relaciones familiares juegan una papel mucho más importante que en el mundo anglosajón (Pichardo 2009). Sin embargo, no es despreciable el dato de que un $48 \%$ de las personas encuestadas haya selecciona- 
do a las amistades como parte de su familia. En el siguiente gráfico se pueden observar las respuestas que ofrecieron a esta pregunta las personas participantes en el Encuentro:

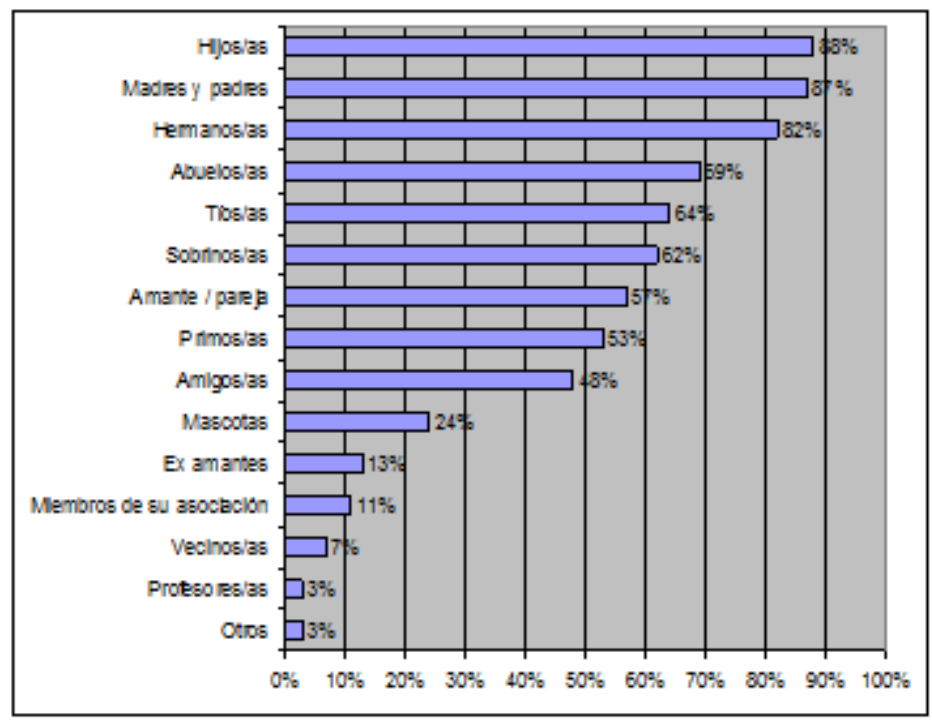

GRÁFICO 2 (autoría propia).

Sería interesante observar, en futuras aproximaciones, de qué manera los miembros de familias con diferentes estructuras - monoparentales, en cohabitación o recompuestas, por ejemplo- sean heterosexuales u homosexuales, valoran la pertenencia de las amistades a su estructura familiar.

\section{LA CUESTIÓN DE LA ELECCIÓN}

"Es el amor lo que crea la familia: ni más ni menos" Lema de la segunda marcha a Washington por los derechos de las lesbianas y los gays de 1987.

A partir de la obra de Weston (2003), mucho se ha debatido y teorizado para contribuir a la deconstrucción del parentesco tradicional iniciada por Schneider en la década de los ochenta (1980). Desde la propuesta de Carsten (2007 [1995]) de relatedness — vínculos basados en la solidaridad duradera y difusa- y la propia aportación de "parentesco electivo" de Weston, se ha instalado la idea de que la elección individual era una característica de las homoparentalidades, en una clara contraposición desnaturalizadora de los lazos sanguíneos, biológicos y genéticos. Si bien estas aportaciones fueron y son aún necesarias y reveladoras, debemos apuntar que la elección podría considerarse una noción individualista y, si se quiere, vinculada a la cla- 
se social, que basa la formulación de las relaciones con las personas y las cosas en la potestad subjetiva del "yo". Así, Fonseca (2008) advierte de su vinculación con el liberalismo: la elección individual a través de las TRA legitimada por el estado y por la ley, y la capacidad económica y de consumo. Briggs llega a plantear esta provocadora interpretación:

A medida que los derechos van siendo redefinidos explícitamente en términos de libertad de comprar y vender cosas, las familias LGBT consiguen cada vez más, compensar sus aparentes desventajas. Lo que no conseguimos ganar en la arena política -el reconocimiento de que las personas LGBT podemos ser buenos padres y buenas madrespodemos [ahora] ganarlo en el mercado, donde [la definición de esas competencias] se decide cada vez más por el dinero (2005: 11).

Mientras, por ejemplo, una pareja homosexual francesa tenga que desplazarse a Bélgica para acceder a las TRA, deberíamos reparar en que la ley o el dinero hacen que la elegibilidad de una opción u otra sea más o menos accesible. No debemos pues, pasar por alto que en el "mercado reproductivo" hay quienes tienen que aportar dinero para acceder a él (espermatozoides, óvulos, matrices e, incluso hijos/as) y quienes reciben una compensación económica; quienes dan y reciben en adopción, etc. La pregunta que sugiere Fonseca (2008: 7) a este respecto gira en torno a la perspectiva y dirección que adquiere la lucha política de la "elegibilidad": "Estamos más preocupados por los derechos humanos o por los derechos del consumidor?». Es decir, la clase social constituye un límite para el acceso a la paternidad o maternidad del colectivo LGBT.

Tendríamos pues que agregar un factor cultural ligado a las condiciones estructurales que es, por tanto, diverso y cambiante. Los apuntes de Weston sobre las familias de elección provienen de un trabajo de campo realizado en el área de la Bahía de San Francisco que no escapa a las particularidades culturales, sociales e históricas del momento y lugar concreto en que este estudio se llevó a cabo. Mientras tanto, en la sociedad española, la familia tiene una importancia capital en los aspectos económicos, materiales y sociales muy diversas, que nos lleva a pensar que ni las personas homosexuales ni las familias de origen se pueden permitir la exclusión mutua ${ }^{6}$, lo que limita en cierta medida el alcance de la elección puramente individual basada en el yo (Pichardo 2011).

Una vez que comienzan a construirse las identidades LGBT — con iniciativas articuladas organizadamente desde el propio colectivo y no desde "afuera" por el mundo heterosexual-, con el aumento de las reivindicaciones públicas y la visibilidad de este colectivo, comienza un proceso de institucionalización del universo homosexual que trajo consigo la retórica de los derechos. Particularmente, de la igualdad de derechos. Esta retórica ha ido adaptándose a reclamaciones concretas que en cada lugar del mundo han tenido que acomodarse a las especificidades contextuales e históricas. En especial, por reciente y relevante ${ }^{7}$, podemos destacar la movilización por

\footnotetext{
${ }^{6}$ Este podría ser uno de los motivos principales de la aceptación de las relaciones homosexuales para las familias españolas (Pichardo 2009).

${ }^{7}$ Las últimas movilizaciones en España reclamaban una resolución declinante del recurso de anticonstitucionalidad del matrimonio igualitario a presentado por el Partido Popular. Finalmente, el Tribunal Constitucional desestimó este recurso el 6 de noviembre de 2012.
} 
el igual derecho a contraer matrimonio. Así, el matrimonio, la institución considerada como uno de los pilares de la opresión heterosexista, se convirtió en uno de los principales campos de batalla, en un camino con gran potencial para acceder a la ciudadanía y a la inclusión, legitimando - y dando cobertura y derecho- a dar y recibir cuidados, herencia y el resto de expectativas sociales que se colocan sobre las relaciones familiares. Si "la frontera entre amigos y parientes se borró para mezclar a todos aquellos que han demostrado su amor estando ahí cuando se los necesitaba" (Fassin 2011: 8), el amor deviene el símbolo central de la homoparentalidad y sortea el supuesto procreativo implícito en la unión heterosexual y los lazos de sangre. Es una suerte de producto y fundamento simbólico de las familias homoparentales: "a él se asocian estrechamente las prácticas a través de las cuales las personas establecen y confirman una solidaridad mutua y duradera" (Weston 2003: 159).

El "derecho a amar" ${ }^{8}$ fue y es uno de los principales argumentos reivindicativos del colectivo homosexual en lo referido a la lucha por la consecución de derechos ligados a la parentalidad y el parentesco. La retórica del amor está llamada a equilibrar la imagen de la homosexualidad vinculada a la inestabilidad y el riesgo (Villaamil 2004) — sea en la sexualidad, en la salud, etc.- apelando a valores universales y deseables que establezcan equivalencias con la heterosexualidad. El amor aparece como un criterio necesario y suficiente para justificar la reivindicación de los derechos al parentesco, pero también para negarlos. Esto es, la significación de los derechos se ha convertido en un campo de batalla simbólico en el que se enfrentan diversas posturas esgrimiendo las mismas retóricas sobre el amor. Así, frente al derecho fundamental de los niños/as a ser amados —esgrimido por quienes defienden la homoparentalidad - se enfrenta el pretendido derecho a tener una madre y un padre apelado desde los sectores más heteronormativos y conservadores de la sociedad.

A la vista de estas evidencias, no es posible negar que tanto la parentalidad como el parentesco son cuestiones altamente políticas que atraviesan los límites de lo personal y que instan a la reflexión de la sociedad al completo.

\section{FAMILIAS "COMO LAS DEMÁS"}

Si en toda definición relacional, "la yuxtaposición de dos términos confiere significado a ambos" (Saussure en Weston 2003: 59), la inter e intra objetivación y subjetivación de las familias LGBT guardará una estrecha relación con el modelo hegemónico de familia nuclear heterosexual. Sin embargo, al interior del colectivo de familias homoparentales y también en las aproximaciones analíticas que ponen el énfasis en la creación de un nuevo tipo de familias, se alude en numerosas ocasiones a la ausencia de modelos, a la posibilidad creativa que esto permite y a la necesidad de encontrarlos.

Que las familias homoparentales no sean familias meramente sustitutas o imitadoras de los vínculos de sangre perdidos o de otros vínculos familiares creados en otras

\footnotetext{
${ }^{8}$ Durante el Encuentro se estrenó el documental Right 2 love (Derecho a amar) que recogía la historia de siete familias homoparentales europeas con hijos/a. Disponible en: <https:// www.youtube.com/watch?v=3z6nXxmpZ6Y>.
} 
esferas de la sociedad, no significa que partan de cero por la ausencia de modelos: "las relaciones entre personas del mismo sexo no escapan necesariamente a las presiones sociales de imitar las prevalentes normas del sexo: heterosexual, coital, en relaciones de pareja, monógamas, en casa, no comerciales, por amor, y entre miembros de la misma generación" (Rubin en Takács y Kuhar 2011: 27). Como tampoco escapan de las prevalentes normas de la institución familiar hegemónica. Así, las familias LGBT están en constante relación con esos modelos: se reflejan, contestan, modifican y están en tensión o diálogo con el modelo heterosexual de familia nuclear en una relación dialéctica. Al tiempo, devienen realidades normadas que les son aplicadas a los padres y madres homosexuales como una suerte de vara de medir la idoneidad parental.

Si el discurso de normalidad aparece a menudo entre las familias LGBT, debemos tener en cuenta lo que trae consigo la puesta en práctica de esa normalidad. Para recoger la percepción que tienen los padres y madres homosexuales respecto a la especial atención que pone la sociedad patriarcal y heterosexual sobre sus cualidades y capacidades para afrontar la parentalidad, planteamos en el cuestionario varias temáticas que analizaremos a continuación.

Propusimos a las personas asistentes que nos confiaran si se sentían bajo la presión de ser padres y madres "perfectas" por pertenecer a una familia homoparental. Un $32 \%$ de las personas que contestaron esta pregunta afirmaron sentirse presionadas para ser buenos y buenas padres y madres, frente a un $68 \%$ que afirmaron no sentir dicha presión. En muchas ocasiones, esa negativa vino acompañada de una aclaración con muchas referencias a la discriminación desde diferentes aproximaciones, resaltando la constante vigilancia a la que son sometidos y sometidas a diferencia de las familias heterosexuales. Un padre entrevistado comenta: "si fallas [en la maternidad o paternidad] serás castigado de manera más severa y se atribuirá a tu condición sexual".

Se hacen numerosas alusiones al control ejercido sobre el entorno de los niños y niñas, para contrarrestar la influencia de referentes negativos, como la influencia heterosexista. Los padres y madres reflejan una actitud proactiva en cuanto a la prevención de cualquier tipo de agresión contra sus hijos e hijas. Explícitamente se señala la orientación sexual de los padres o madres como una causa potencial de trato discriminatorio. También está presente la autopercepción de discriminación hacia el modelo familiar homoparental y la homofobia. De esta manera, observamos algunas referencias a la parentalidad "perfecta" como una respuesta directa a la discriminación social hacia la realidad familiar LGBT.

Sin embargo, también estuvo presente el discurso de que el hecho de pertenecer a una familia LGTB no influye en la presión percibida en cuanto al ejercicio de la parentalidad. Podemos aventurar que se asume la existencia de diferencias entre las familias homoparentales y otros modelos familiares y que son percibidas por los encuestados/as como negativas; lo que, según las respuestas, resulta en una normalidad impuesta, un exceso de normalidad, que pretende obviar las diferencias entre los modelos familiares, para ser como una "familia normal".

Otra manera de hacer explícita cualquier percepción de presión negativa hacia el modelo homoparental era recoger las impresiones de los asistentes respecto a la existencia o no de sobreprotección de sus hijos e hijas. A este respecto, un $34 \%$ de las 
personas que contestaron esta pregunta manifiesta que los padres y madres de familias LGBT efectivamente sobreprotegen a sus hijos e hijas, frente a un 64\% que considera que no los sobreprotege. Teniendo en cuenta que la mayoría de las personas que respondieron a esta pregunta contestaron que no sobreprotegían a sus hijos e hijas, vemos que este hecho podría corresponderse con el discurso dominante del colectivo respecto a la normalidad.

Por otro lado, la gestión de las distintas situaciones familiares se percibe como performativa en el sentido en el que se ven en la necesidad de demostrar constantemente su capacidad de ejercer la paternidad y la maternidad desde su realidad LGBT. La sociedad, encarnada en familiares, vecindario, medios de comunicación, escuela y otros contextos sociales, exige una justificación por confiarle a la homoparentalidad la reproducción social.

Las personas encuestadas también fueron consultadas acerca de la posibilidad de que el ser miembro de una familia LGBT tuviera algún tipo de influencia en la vida de sus hijos e hijas, a lo que un $84 \%$ contestó afirmativamente, mientras que un 16\% respondió de forma negativa. En el apartado de respuesta abierta a esta pregunta podemos observar que se utilizan dos concepciones de la diferencia. Por un lado se plantea la diferencia como algo negativo: el colectivo es considerado como una minoría discriminada, lo que les hace vulnerables. Consideran entonces que los niños/as de familias LGBT deben ser fuertes para enfrentarse a las discriminaciones a las que se verán expuestos/as. Por otro lado, la diversidad es entendida como un valor que tiene consecuencias positivas en los niños/as de familias LGBT. También fue frecuente la mención de la tolerancia, el respeto, la igualdad, la sensibilidad y la conciencia, así como mayor apertura mental como principales características de los niños y niñas de familias LGBT. Esto nos hace cuestionarnos si es que no sólo las familias LGBT tienen que ser normales, sino que quizás también se corre el riesgo de colocar sobre los hijos e hijas criados en estas familias la expectativa de ser "mejores que los demás»: mostrando más respeto a las diversidades, mayor sensibilidad, etc.

\section{GÉNERO Y PARENTESCO LGBT}

Las familias LGBT desafían conscientemente la división sexual de las tareas domésticas así como la idea de que la reproducción es propia de las mujeres y la protección y provisión propia de los hombres. Durante el encuentro, se hace referencia constante a la necesidad de romper con la estructura patriarcal y con la imposición de los roles de género. Sin embargo, ni tener una posición política al respecto, ni la patente reflexividad del colectivo sobre estas cuestiones implican un cambio de prácticas automático, instantáneo o radical.

Adquiere aquí una gran importancia el trabajo de campo etnográfico para abordar la compleja relación entre los discursos y las prácticas relativas a los roles de género entre las familias homoparentales. El trabajo etnográfico expone que, si bien existen rupturas en este campo, también existen continuidades tales como la externalización de las tareas domésticas a través de madres, abuelas o empleadas de hogar en el caso de algunas parejas de hombres (Pichardo 2009). Se pone así de manifiesto que en el interior de una pareja los roles de género pueden ser horizontales y equilibrados, pero 
es posible continuar reproduciendo el ordenamiento clásico de las tareas domésticas de una forma más sutil sólo accesible a través de la observación etnográfica.

Cadoret propone una reflexión en relación al género y al parentesco partiendo del análisis de un caso particular en el que una pareja de hombres decide tener un hijo/ a a partir de una subrogación, llevada a cabo en Estados Unidos, en la que se utilizan óvulos de dos mujeres distintas que se desarrollarán en el útero de una tercera mujer (2009; 80-81). Cadoret consulta en una entrevista a Basile, el miembro de la pareja que aportó el semen para el desarrollo de los embriones, si no sería posible una distribución diferente a la de la designación de los padres como padre y madre a cómo la habían distribuido en los documentos completados en Estados Unidos para la construcción legal del parentesco de sus hijos, nacidos allí. Partiendo del dato de que el entrevistado era el único padre con una conexión biológica en esta configuración familiar, Cadoret se basa en cuatro argumentos fundantes del parentesco: 1) es el cuerpo que da a luz lo que convierte a la mujer en madre; 2) el padre normalmente lo es por ser el compañero o marido de la mujer; 3) sólo figuraban los términos "madre" y "padre" en los formularios de parentesco; 4) en el caso narrado el único cuerpo biológicamente presente es el del Basile; para preguntarle a Basile ipor qué no figurar en la casilla reservada para la madre? Pero la respuesta a la pregunta es negativa: Basile respondió que él era el padre, no la madre. Así, Cadoret concluye que se apoya en su identidad masculina para asentar el parentesco.

Es interesante pues pensar que si bien se rompe con la heterosexualidad de la pareja parental, no es tan fácil contestar una identidad relacionada con las atribuciones genéricas y sexuadas dominantes de los cuerpos y personas. No se propone pues, la indiferencia de los sexos, sino la apertura de los esquemas parentales. Puede que sea posible reflexionar sobre los roles y acciones en algunas dimensiones de la vida social, conyugal, parental, pero otros aspectos del sistema sexo-género son más difíciles de abordar.

\section{MONOPARENTALIDADES Y PARENTALIDADES TRANS}

En el caso del II Encuentro Europeo de Familias LGBT, se aprecia un notable esfuerzo por parte de la organización para representar la diversidad de las familias homoparentales tanto en la cartelería y la publicidad, como en las temáticas tratadas en las conferencias. Asimismo, en la Memoria Final del Encuentro se declaraba que: "Las familias homoparentales son modelo ejemplar de diversidad en sí mismas: monoparentalidad, familias reconstituidas, familias multirraciales, familias intergeneracionales y familias transexuales, entre otras, son una realidad que se reconoce en el colectivo" (FLG 2012: 6). A pesar de estos esfuerzos, las representaciones más extendidas no contemplaban el abanico de diversidades que pueden existir dentro de los llamados nuevos modelos familiares. El modelo familiar que apareció sobrerrepresentado fue el que reflejaba el modelo de familia nuclear, compuesta por dos personas en pareja, con hijos/as y que comparten residencia. Tampoco se constataba una relevante presencia física de familias monoparentales, sin hijos/as (en caso de reconocerse como familias más allá de haber decidido no tener descendencia), familias transexuales, reconstituidas, poliamorosas, intergeneracionales, multiétnicas, transnacionales, etc. 
Tomando el caso de las familias monoparentales, podemos abordar el cuestionamiento del tradicional binomio constitutivo de la familia nuclear: pareja + hijos/as. Puede reconocerse como pertinente el análisis que proponen Jociles y Rivas (2010) acerca de las madres solteras por elección. Estas autoras postulan que muchas veces el vínculo de pareja es pensado como una faceta individual que atañe a la mujer - O al hombre, pensando en los padres solteros por elección- y de forma indirecta puede incluir a los hijos o hijas, pero inicialmente no forma parte del proyecto familiar. El Encuentro ofrecía un espacio llamado "ágora" para albergar las propuestas e intereses de las personas asistentes más allá de lo organizado oficialmente desde el Comité Organizador del Encuentro. Una asistente propuso un taller titulado «Personas solteras que quieren tener hijos". En este taller, una de las participantes señalaba: "más allá de la pareja, la maternidad sigue".

La realidad expone que tener una relación afectivosexual, no es condición sine qua non para acceder y/o mantener la parentalidad, aunque pueda diferenciarse entre aquellas personas que deciden ser madres o padres en solitario — sin tener en cuenta la necesidad de una pareja para tal proyecto- y aquellas a las que esa soledad les sobreviene. A partir de esta disociación es posible pensar en cómo algunos casos, por ejemplo los de adopción internacional (en los que los trámites de adopción pueden extenderse más de 2 años en España) pueden ser un ejemplo de que las relaciones afectivosexuales "van y vienen", en palabras de las asistentes a ese taller, y surge la necesidad de "separar la maternidad y la paternidad de la pareja".

Uno de los retos característicos que se le atribuyen a la monoparentalidad es la necesidad de crear o pertenecer a redes de apoyo más amplias que lo que se entiende por familia en sentido restringido. Estas redes permiten cubrir tanto las necesidades de los hijos e hijas, como las de los padres y madres que no cuentan con una pareja para organizar su vida cotidiana. En este mismo taller se explicitó cómo madres y padres singles de Valencia, gracias a internet, están en continuo contacto y utilizan una página web para intercambiar información y servicios ${ }^{9}$. En realidad estas redes no suelen ser de uso exclusivo de familias monoparentales LGBT. De hecho, habría que reflexionar acerca de si en este tipo de espacios la sexualidad de el/la progenitor/a es de carácter público y si las relaciones se organizan teniendo como base esa particularidad, o si, por ejemplo, es la parentalidad en solitario la que funciona como conectora. Sería interesante pues pensar en las variables que se reconocen y explicitan como fundadoras de esas relaciones.

Otra de las realidades minoritarias menos representadas y visibilizadas incluso dentro del propio colectivo LGBT es la de las personas transexuales, situación particularmente crítica si pensamos en las parentalidades transexuales. Durante el Encuentro tuvo lugar un grupo de trabajo denominado "Maternidad/paternidad Trans" donde surgieron las principales preocupaciones y retos de este colectivo.

Marina Sáenz, abogada transexual ponente en el Encuentro, defendió la transexualidad como "una forma de ser persona" y denunció la invisibilización que sufren tanto en la sociedad como dentro del mismo colectivo LGBT, donde también hay que dar cuenta de los prejuicios existentes hacia las personas que se acogen bajo una misma identidad, pero con otra realidad. Debido a esta falta de visibilización y por el des-

\footnotetext{
${ }^{9}$ Disponible en: <www.singlesvalencia.es/group/papisymamissingle>.
} 
conocimiento de su realidad, se ven sometidos/as a una doble discriminación y han de enfrentarse a una doble lucha. Marina declaró que los derechos de gays y lesbianas son más reconocidos y el colectivo transexual va siempre un paso por detrás; como resaltó una persona trans durante el debate: "hace unos años la idea de dos hombres teniendo un hijo era impensable, sin embargo habéis conseguido antes la idea de un 'gay padre' que nosotras la idea de una maternidad o paternidad trans".

Durante el debate se alude a la Declaración Universal de los Derechos Humanos y se denuncia que, pese a que establece la igualdad y la no discriminación por razón de sexo, identidad sexual o identidad de género, en la aplicación de las leyes existe un comportamiento contrario. Si ya existen dificultades para acceder a la maternidad y paternidad para personas y parejas gays o lesbianas, las dificultades para acceder a la parentalidad para personas trans son aún mayores.

Efectivamente, una de las mayores dificultades a las que se enfrentan las personas trans se evidencia a la hora de acceder a la parentalidad, ya que debido a la patologización de su condición se ven sometidas a una esterilización forzosa producto de la medicalización que les es impuesta. Ahora bien, la reasignación de género no es un impedimento per se para acceder a la parentalidad: muchas personas se plantean la congelación de esperma y óvulos antes de proceder a la transición por si surgiera con posterioridad el deseo de tener hijas o hijos biológicos. Durante el debate, se manifestó la preocupación por las tempranas edades a las que en algunos casos comienzan las reasignaciones, lo que iría en detrimento de la posibilidad de decidirse a acceder en un futuro a la parentalidad.

Existen otras vías como la adopción —iqué dificultades específicas puede encontrar una persona trans o una pareja con un miembro trans que quiere adoptar? - o el hecho de iniciar el proceso de transición de género una vez se ha sido padre y madre, con lo que ello puede suponer a la hora de generar separaciones y/o divorcios (aunque no siempre sea el caso) y, sobre todo, en escenarios de disputa por la custodia de menores.

La organización del Encuentro incluyó a una familia trans en la cartelería del mismo y en el video institucional que produjeron para la ocasión, contribuyendo de forma decidida a la visibilización de este tipo de familias. Así, y gracias al trabajo de campo durante el Encuentro, pudimos dar cuenta de que las familias homo-monoparentales y las parentalidades trans manifestaban la importancia de reivindicar su existencia dentro del propio colectivo de familias LGBT y se consideraban doblemente invisibilizadas; en palabras de una entrevistada: "una minoría dentro de una minoría".

\section{CAMBIOS Y CONTINUIDADES}

Hemos intentado dar cuenta de que lo que pudiera aparentar ser resistencia o reproducción del modelo hegemónico de familia y parentesco debe ser analizado teniendo en cuenta los contextos de producción de estrategias discursivas y prácticas, por lo que no debemos desatender la multiplicidad de actores y factores involucrados en el campo familiar: leyes que dictan el perfil del adoptante y adoptado, políticas públicas que consideran la infertilidad como una enfermedad o no, compañías de seguros que orientan los beneficios para un tipo de gestante u otro, bancos de es- 
perma que facilitan la elección del donante, tecnologías que permiten congelar esperma para así reutilizarlo con el fin de generar una fratría consanguínea, etc. son todos coproductores de las formas, sentidos y valores familiares de nuestra época (Jasanoff en Fonseca 2008: 7). Sin embargo, debemos destacar que el Estado da existencia y realidad a la familia, y por lo tanto, sus concepciones - aun no siendo las únicas- tienen un importante papel en las definiciones de lo que se entiende como familia.

Teniendo en cuenta esta compleja relación entre rupturas y continuidades, la consecución de derechos, como el acceso al matrimonio igualitario, la legitimación de la filiación a través de las TRA y la adopción, la conquista por parte de la homoparentalidad de espacios públicos antes vedados, o la creciente visibilización y normalización de estas familias, nos preguntamos si no es acaso necesario repensar la validez de las "familias LGBT" como unidad de análisis de estudio antropológico. La pregunta en definitiva sería: ¿qué es lo que sigue manteniendo la frontera entre el mundo heterosexual y el mundo homosexual?

Esta reflexión precisa de un extenso debate para ser abordada. Sin embargo, podemos apuntar algunas aproximaciones que pueden contribuir al análisis. Por un lado, el estudio de la homoparentalidad ha contribuido a la reevaluación del estatus del parentesco clásico y nos anima a continuar trabajando en la desnaturalización del modelo biogenético para pensar la familia "no tanto como un sustantivo, sino como un adjetivo o, posiblemente, un verbo" (Morgan en Takács y Kuhar 2011: 11), aludiendo de alguna manera a los aspectos procesuales y socialmente construidos de la familia y del parentesco (Carsten 2007: 516). Por otro lado, aunque las familias LGBT cuenten con muchos puntos de contacto con las familias heterosexuales - por ejemplo en algunas de las formas de acceso a la parentalidad-, una variable independiente que las particulariza es la exposición a la homofobia que puede afectar a madres, padres, hijos, hijas e incluso la propia familia de origen.

Además, debemos advertir que el modelo más estudiado y representado niega las formas emergentes de familia fuera - pero también dentro- del colectivo LGBT: monoparentalidad, parentalidad trans, coparentalidad, relaciones entre más de dos personas, entre otras. Es por ello que la homoparentalidad debe ser objeto de estudio por sí misma, tanto por cuestiones analíticas como por cuestiones políticas y debemos, eso sí, ponerla siempre en relación con otras formas de familia.

Finalmente, el llamado parentesco electivo del colectivo LGBT no es una "nueva forma de parentesco", por el contrario, en un complejo proceso de agencia y reflexividad se contesta con sus rupturas y continuidades el parentesco tradicional tomándolo como punto de partida y dando lugar a una transformación creativa. Esta posición teórica y política defiende que no podemos considerar que las familias LGBT ocupan una esfera subsidiaria del parentesco (Weston 2003). Tampoco podríamos denominarlas como una minoría dentro del parentesco, sino que los procesos de transformación creativa del parentesco tradicional que este colectivo lleva adelante implican la revisión y redefinición del parentesco en su conjunto y de forma relacional, sea homosexual o heterosexual, tanto en el nivel de reflexión teórica que se lleva a cabo en las ciencias sociales, como en las prácticas de los agentes y en la construcción y deconstrucción de las normas legales y culturales. 


\section{BIBLIOGRAFÍA CITADA}

Briggs, L. 2005. Gay families, neoliberalism, and organ theft. LGBT studies: Brown Bag, [en línea], disponible en: <http://www.u.arizona.edu/ lbriggs/>.

Cadoret, A. 2003. Padres como los demás. Homosexualidad y parentesco. Barcelona: Gedisa.

Cadoret, A. 2009. "Parentesco y figuras maternales. El recurso de una gestante subrogada por una pareja gay”. Revista de Antropología Social 18: 67-82.

Carsten, J. 2005. "La sustancia del parentesco y el calor del hogar: alimentación, condición de persona y modos de vinculación (relatedness) entre los Malayos de Pulau Langkawi", en R. Parkin y L. Stone (eds.), Antropología del parentesco y de la familia: 515-542. Madrid: Ed. Universitaria Ramón Areces.

Donoso, S. 2002. "Epílogo: La familia lésbica”, en G. Herdt y B. Koff (eds.), Gestión familiar de la homosexualidad: 171-213. Barcelona: Bellaterra.

Fassin, E. 2011. "Foreword. When parallels meet: the family of sex and the sexualisation of the family", en J. Takács y R. Kuhar (eds.), Doing families. Gay and lesbian family practices: 7-10. Liubliana: Mirovni Institut.

FLG - Associació de famílies Lesbianes i Gais (2012) Memoria Final del II Encuentro de Familias LGBT, [en línea], disponible en: <http://www.familieslgtb2012.org/images/stories/pdf/memoria_final_cast.pdf>, [consultado el 06/04/2015].

Fonseca, C. 2008. Homoparentalidade: o ponto alfa do parentesco?, [en línea], disponible en: <http:/ /www.nigs.ufsc.br/claudia_fonseca.pdf> [consultado el 06/04/2015].

Francesch, A. 2012. "Los nuevos modelos de turismo: las NTRA", en N. Konvalinka (ed.) Modos y maneras de hacer familia: 131-144. Madrid: Biblioteca Nueva.

Jociles, M. I. y A. Rivas. 2010. "Es la ausencia del padre un problema? La disociación de los roles paternos entre las madres solteras por elección". Gazeta de Antropología, 26(1): art. 04, [en línea], disponible en: <http://www.ugr.es/ pwlac/G26_04Isabel_Jociles-AnaMaria_Rivas.html>, [consultado el 06/04/2015].

Meillassoux, C. 2001 Mythes et limites de l'anthropologie. Le Sang et les Mots. Lausana: Editions Page deux.

Pichardo, J. I. 2009. Entender la diversidad familiar. Barcelona: Bellaterra.

Pichardo, J. I. 2011. "Sex and the family: intersections between family, gender, reproduction and samesex sexuality in Spain", en J. Takács y R. Kuhar (eds.) Doing families. Gay and lesbian family practices: 17-36. Liubliana: Mirovni Institut.

Piella, A. y V. Fons. 2010. "Introducción", en V. Fons, A. Piella y M. Valdés (eds.) Procreación, crianza y género. Aproximaciones antropológicas a la parentalidad: 13-23. Barcelona: PPU.

Rivas, A. 2008. "Las nuevas formas de vivir en familia: el caso de las familias reconstituidas". Cuadernos de Relaciones Laborales 26(1): 179- 202.

Schneider, D. 1980 American Kinship. A cultural Account. Chicago: The University of Chicago Press. Segalen, M. 1992. Antropología histórica de la familia. Madrid: Taurus.

Takács, J. y R. Kuhar. 2011. Doing Families. Liubliana: Mirovni Institut.

Villaamil, F. 2004 La transformación de la identidad gay en España. Madrid: Catarata.

Weston, K. 2003. Las familias que elegimos. Lesbianas, gays y parentesco. Barcelona: Bellaterra.

Fecha de recepción: 9 de febrero de 2015

Fecha de aceptación: 2 de marzo de 2015 